\title{
EXPERIMENTAL AND NUMERICAL MODELING OF FLUID-SEABED INTERACTION IN SHALLOW WATER
}

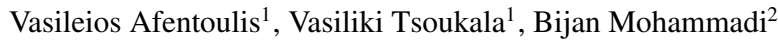

For the design and the construction of the defence structures against beach erosion, there is a need to predict and understand the evolution in time of the shape of the sea sandy bed, using different numerical models and control theories. In the present paper a numerical model based on shallow water equations, which is an application of control theory to the evolution of sandy bed, is used in order to propose a formulation for the wave motion based on fluid and structure coupling, using minimization principles. Furthermore, measurements from a physical experiment are used in order to verify the accuracy of the model. The experiment was carried out in a multi directional wave basin at the SOGREAH (LHF facility, G-INP, France) and provided extensive measurements and detailed analysis of combined hydrodynamics and morphodynamics, suggesting a subtle interplay between several feedback mechanisms associated to wavedriven rip current circulations, wave nonlinearities, sediment transport, and seabed evolution. Using the numerical model, wave characteristics and depth profiles have been calculated and compared to experimental results.
\end{abstract}

Keywords: Sandy beach morphodynamis; fluid-bed interaction; beach erosion; sediment transport; numerical modeling; shape optimization; hydrodynamics

\section{INTRODUCTION}

Engineers build various types of maritime structures. Breakwaters and quay walls for ports and harbors, seawalls and jetties for shore protection, are some examples. These structures must perform their functions in the natural environment, being subjected to the hostile effects of winds, waves, tidal currents, earthquakes, etc. To ensure their designated performance, we must carry out comprehensive investigations in order to understand the environmental conditions. The investigations must be as accurate as possible so that we can rationally assess the effects of the environment on our structures (Goda, 2000). Complex multi-physics fields formed by dynamic interactions between fluid flows, seabed profile evolution, and seabed response are natural in a marine environment (Nakamura and Mizutani, 2014). The ability of wind-generated waves to suspend sediment material is a direct function of wave amplitude and frequency and inversely proportional to water depth (Krone, 1978). However, because of the "One step forwards and one step backwards" nature of the wave motion, the currents may still be very important transporters of wave entrained sediments unless the sediment concentrations vary periodically in step with the wave motion (Nielsen, 1992). Motion of the nearshore bed is not a linear function of velocity magnitude or direction, so it is likely that there is a role for the various mechanical properties of the bed (Austin and Buscombe, 2008). The response of bed evolution to the coastal processes has also different time spans, ranging from that of an individual event, through to seasonal variation in driving forces.

Modeling and simulation of such fluid-sediment seabed interactions is essential for the construction of the defence structures against beach erosion, which result in the reduction of the incoming wave energy at the shoreward locations. To deal with this type of interaction phenomenon, a numerical model based on shallow water equations, is presented in order to propose a formulation for the wave motion based on fluid and structure coupling using minimization (Bouharguane and Mohammadi, 2012), (Mohammadi and Bouchette, 2014). Minimization principles have been used many times in the past to design defence structures against beach erosion (Azerad et al., 2005), (Isebe et al., 2008). In these works, the designed structures were independent of time and were built once for all. Hence, this method goes one step further giving the possibility to the structure to change in time. It is worth pointing out that the the fundamental assumption of this proposed method is the fact that bed adapts to the flow by some sort of optimal sand transport in order to minimize some energy expression, optimal transport is seen here as minimal change in the bed shape. The time scales of interest are below a day and recoveries between storms or seasonal and inter-annual variabilities are out of scope.

Measurements from a physical experiment have been used in order to verify the accuracy of the model. This experiment was performed in 2008, in the LHF (Laboratoire d'Hydraulique de France), providing for the first time an extensive quantitative description of the morphodynamics of a rip current system during intermediate beach down-state and up-state transitions (Castelle et al., 2010), (Michallet et al., 2013),

\footnotetext{
${ }^{1}$ Laboratory of Harbour Works, Department of Water Resources and Environmental Engineering, School of Civil Engineering, National Technical University of Athens, Iroon Polytechniou 5, 15780 Athens, Greece.

${ }^{2}$ Institut Montpellierain Alexander Grothendieck, Universite de Montpellier, 34095 Montpellier cedex 5, France
} 
(Michallet et al., 2010). As derived from the experimental results, the changes in prevailing wave conditions increase the rate at which the beach morphology evolves. This interaction has been also investigated, using the proposed numerical model and applying as initial conditions the same wave climates as that of the experimental set-up.

\section{THE NUMERICAL MODEL}

\section{Description of the method and assumptions}

This model is an application of control theory to the evolution of sandy bed and the main aim is to propose a formulation for the wave motion based on fluid and structure coupling using minimization principles. For the purpose of this study the sea bed is seen as a structure with low stiffness, and this structure is changing in time. One of the main ingredients in the chain of control is the cost function to be minimized. One expects the bed to act as flexible structure and to adapt to flow conditions in order to minimize some energy-based functional.

For the definition of the approach two dimensional situations with a realistic flow model in shallow domains have been considered. The sea bed $\psi: \Omega \subset \mathbb{R}^{2} \rightarrow \mathbb{R}^{+}$changes with time following the changes in the state given by the flow conditions $\mathrm{U}, \psi$ is a univocal function with some regularity. A bed parameterization has been used, based on the the bathymetry given at all the nodes of the fluid mesh. The model for the sea bed evolution is based on minimization of a time dependent functional $J(\psi, U(\psi))$ where $U(\psi)=U(\psi, \tau, x, y), \tau \in[t-T, t],(x, y) \in \Omega$ gathers the state evolution in time, solution of a state equation.

In order to describe the flow motion, shallow water equations have been used as state equation with $U={ }^{t}(h, h u)$ where $u={ }^{t}(u, v)$ is the depth-averaged velocity with $u$ and $v$ the scalar components in the horizontal directions and $h$ the local water depth:

$$
U_{t}+F(U, \psi)=0
$$

where

$$
F(U, \psi)=\left(\begin{array}{c}
\nabla \cdot(h u) \\
\nabla \cdot(h u \otimes u)+g h \nabla(h+\psi)
\end{array}\right)
$$

Also minimization of $\mathrm{J}$ can be seen as a solution of

$$
\left\{\begin{array}{r}
\psi_{t}=-\rho \nabla_{\psi} J(\psi, U(\psi)) \\
\psi(t=0, x)=\psi_{0}(x)=\text { given }
\end{array}\right)
$$

where $\rho$ is a positive parameter which depends on the local porosity of the bed and quantify its receptivity to flow perturbations. One remarks then that $\rho$ plays the role of the term $1 /\left(1-\lambda_{p}\right)$ in the Exner equation (Paola and Voller, 2005).

$$
\psi_{t}+\frac{1}{1-\lambda_{p}} \nabla \cdot q=0, \quad \psi(t=0, x, y)=\text { given },
$$

where $\lambda_{p}$ is the porosity of the bed and $q$ is the sediment transport flux.

The physical time scales for the fluid and structure (bed motion) are quite different. Indeed, flows have time scales of the order of seconds and the sea bed motion takes place over hours. The cost function involves this state evolution as, for instance, in:

$$
J(\psi, U(\psi))=\int_{t-T}^{t}(j(\psi, U(\psi, \tau)) d \tau
$$

$\mathrm{T}$ indicates a time dependency window and also permits to introduce a difference in time scales between sea bed and flow motions. One can, for instance, consider an energy made of water mechanical energy and involving a constraint on sand displacements requiring minimal topobathmetry changes from the bathymetry $\psi(t-T)$ at the beginning of a time interval of influence $[t-T, t]$ :

$$
J_{1}(\psi)=\int_{t-T}^{t} \int_{\Omega}\left(\frac{1}{2} \rho_{w} g \eta^{2}+\rho_{s} g(\psi(\tau)-\psi(t-T))^{2}\right) d \tau d \Omega
$$

Where $\Omega$ is the physical domain, $\rho_{w}$ and $\rho_{s}$ are respectively the water and sand density and $\eta$ is the deviation of the wave elevation from a low frequency component evaluated using a time interval $\mathrm{T}$. This is a function of space and time and also depends on the bathymetry : 


$$
\eta(x, y, \psi, t)=h(x, y, \psi, t)-\frac{1}{T} \int_{t-T}^{t} h(x, y, \psi, t) d \tau
$$

This functional aims at reducing both wave elevations and changes in the bed shape. A fundamental idea motivating the introduction of the second term in functional $J_{1}$ is the concept of optimal transport. In other words, one thinks that the bed will adapt to the flow in some optimal way in term of sand transport.

\section{Flow solver}

Shallow water equations are discretized by a finite volume formulation (Eymard et al., 2000). This finite volume implementation preserves steady state solutions on non flat sea beds in the absence of perturbations. Four boundary conditions are applied in slip, inlet, shoreline and outlet boundaries. The use of slip boundary condition is of great importance, since the purpose of this study is to identify the interaction which occurs across the bottom boundaries. The outlet condition is a transmissive boundary condition. Values at boundary cells are obtained by second order extrapolations normal to the boundary from the values inside the domain. To describe incoming waves we are use an absorbing/generating inlet boundary condition where the values of water depth are prescribed. In open sea we allow for reflected waves to freely exit the domain. Time integration is explicit for the flow. Due to what we said on the difference of time scales between fluid motion and changes in sea bed, several time step will be taken, typically 100 seconds, in the flow solver before a new step by the bed model described by minimization iterations.

\section{PHYSICAL EXPERIMENT}

\section{Description of experimental Set-up}

The laboratory experiment was undertaken during a 5 week period in a multidirectional wave basin at the SOGREAH (LHF facility, G - INP, France). The basin extended $30 \mathrm{~m}$ in both cross - shore and alongshore directions with an offshore wall constituted of 60 independently controlled piston - type wavemakers (Figure 1) (Castelle et al., 2010).

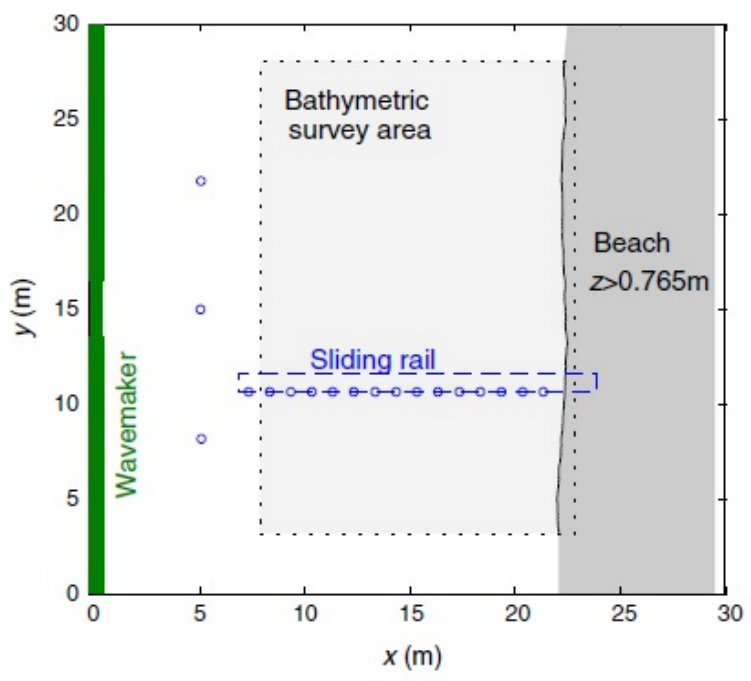

Figure 1: Schematic diagram of the basin with $x$ and $y$, the cross-shore and alongshore coordinates, respectively. The mean water depth is $h_{0}=0.765 \mathrm{~m}$ for $x \leq 6 \mathrm{~m}$. The sandy beach extends from $x=6 \mathrm{~m}$ to $x=26 \mathrm{~m}$. The sliding beam allows for bathymetric survey in the region shaded in grey. Circles indicate positions of the capacitance gauges (Michallet et al., 2013).

A beam sliding on rails supporting the instruments was designed for measuring the waves along crossshore transects and the beach topography (Figure 2). The still water level at the wavemaker was $h_{0}=$ $76.5 \mathrm{~cm}$ for all experiments. Shore-normal irregular waves complying to jonswap spectra were considered. Three categories of wave conditions were applied, defined by their significant wave height and peak period, namely energetic conditions (A: $\left.H_{m 0}=23 \mathrm{~cm} / T_{p}=2.3 \mathrm{~s}\right)$, moderate conditions with a large period (B: 
$\left.H_{m 0}=18 \mathrm{~cm} / T_{p}=3.5 \mathrm{~s}\right)$, or a shorter period $\left(\mathrm{C}: H_{m 0}=17 \mathrm{~cm} / T_{p}=2.1 \mathrm{~s}\right)$. Each experiment consisted of a series of 7 to 24 twenty minute wave sequences, depending on the amount of morphological changes expected.In addition, the generated JONSWAP irregular waves were designed to have less energy at the center of the wave front by imposing a damped motion on chosen wave paddles. This was done in order to create alongshore nonuniformity in the wave breaking for initiating circulations and, as a result, to induce the initial development of the 3- D patterns. The bathymetry was surveyed between each experiment by means of a laser profiler (Michallet et al., 2013).
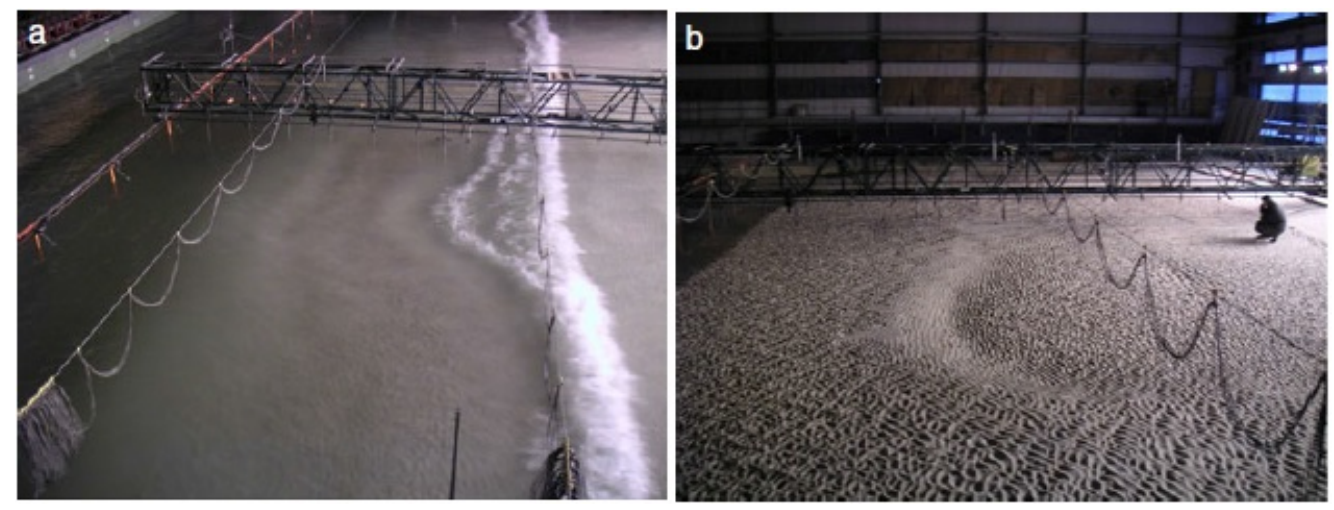

Figure 2: (a) View of a breaking wave front over the threedimensional bathymetry. Wave paddles are seen in the top left corner and the sliding beam supporting the wave gauges $(1 \mathrm{~m}$ apart) and velocimeters are seen on top of the picture. (b) View of the emptied basin during a bathymetric survey showing the presence of a crescentic sandbar and sand ripples (Michallet et al., 2013).

\section{Experimental results}

Alongshore-averaged beach profiles (for 3.12m $\leq y \leq 18.2 m$ ) are shown in Figure 3. An overall accretion of the beach face was first obtained over a $62 \mathrm{~h}$ duration of mainly B wave conditions $\left(H_{m 0}=18\right.$ $\left.\mathrm{cm} / T_{p}=3.5 \mathrm{~s}\right)$. For larger and shorter waves A conditions $\left(H_{m 0}=23 \mathrm{~cm} / T_{p}=2.3 \mathrm{~s}\right)$ between $66: 00 \mathrm{~h}$ and 100:40 h, an overall erosion was observed (Michallet et al., 2013).

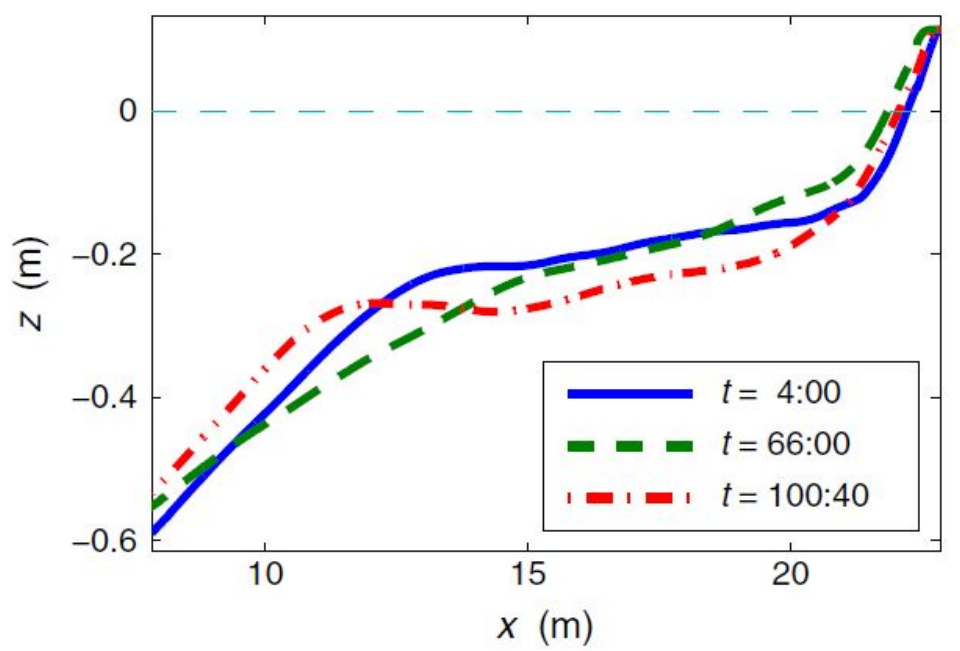

Figure 3: Alongshore-averaged beach profiles at the three main stages of the experiments (Michallet et al., 2013). 


\section{RESULTS AND DISCUSSION}

Model comparisons with experimental data are performed for both waves and beach profiles to ensure that the selected model will yield realistic results. For the simulation of the incoming waves, the water wave elevation at the inlet is represented by the addition of $\mathrm{N}$ monochromatic waves :

$$
h(t)=h_{0}+2 A \sum_{i=1, \ldots, N-1} \sin \left(\frac{\omega_{i}+\omega_{i+1}}{2} t\right) \cos \left(\frac{\omega_{i}-\omega_{i+1}}{2} t\right)
$$

A is the water wave amplitude at inlet, $H_{m 0}$ the water height at rest and $\omega_{i}=2 \pi / T_{i}$ are wave pulsations corresponding to the typical values of periods $T_{i}$.

For the process of the numerical modeling, the case of the experimental wave basin side of $30 \mathrm{~m}$ is considered and the mean water depth is set to $h_{0}=0.765$, so as to compare the hydrodynamic and morphodynamic characteristics in the same field. The predicted wave record compares reasonably with the measured surface elevation. In Figure 4 the wave time series at a specific point of the basin $(x=18.33$, $y=9.27$ ) is presented, as obtained by the experiment and the numerical model. Simply by visual inspection, enough concordance is observed between the numerical and experimental wave periods, but some small deviations are presented in the wave amplitude. This level of precision continue for all the locations of the wave gauges along the cross-shore profiles, thus the selected numerical model could be considered accurate enough to take to the next level of comparison, looking at evolution of the bed shape.

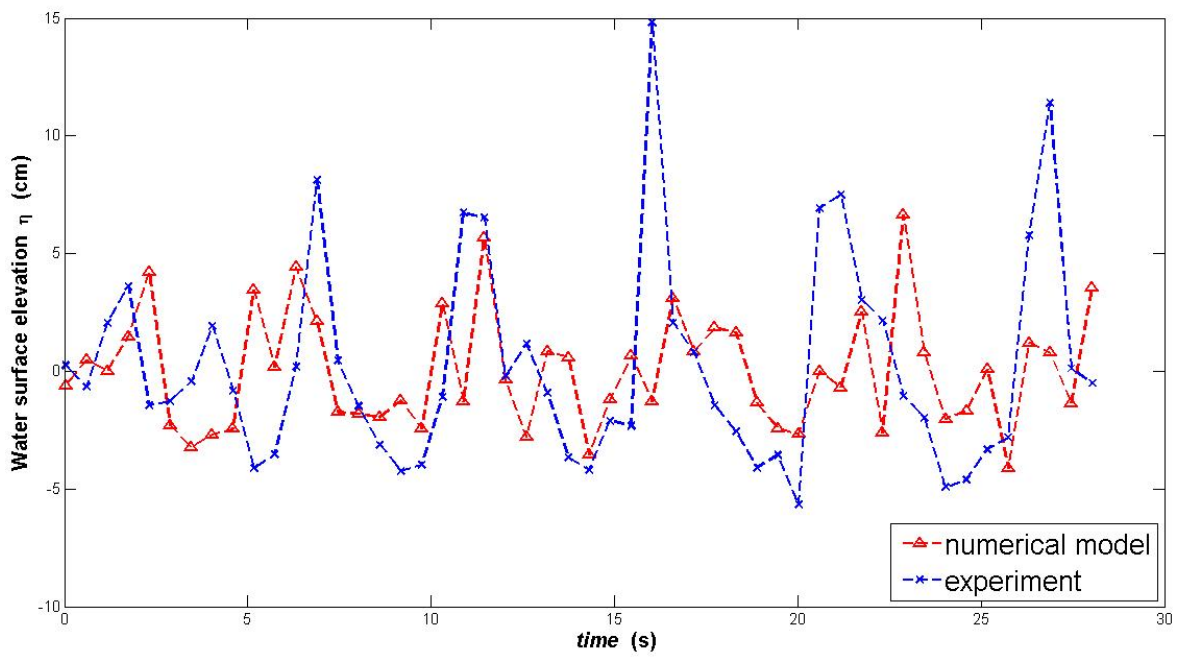

Figure 4: Wave elevation at $(x=18.33, y=9.27)$, as obtained by the numerical model (red line) and the experimental data (blue line).

For the calculation of the sediment transport and the evolution of the beach profiles, the wave climates of the experimental set-up have been considered. Thus, the total simulation duration $(96.4 \mathrm{~h}) \mathrm{has}$ been divided into 2 phases, the 62 hours accretive sequence with B wave conditions $\left(H_{m 0}=18 \mathrm{~cm} / T_{p}=3.5\right.$ s) and 34.4 hours erosive sequence with A wave conditions $\left(H_{m 0}=23 \mathrm{~cm} / T_{p}=2.3 \mathrm{~s}\right)$. These phases correspond to the so-called down-state and up-state wave transitions (i.e., changes from high to low, and low to high wave energies, respectively) (Michallet et al., 2013). Only the section $6 \leq x \leq 26 \mathrm{~m}$ has been taken into account, where the sandy beach extends (Figure 1). It is also worth mentioning that the wave front at the inlet of the numerical model is considered uniform, while for the needs of the experiment, the wave forcing at the wave-maker is set to be alongshore nonuniform. However, some alongshore fluctuations are observed, mainly for the first steps of the numerical simulation before the sandbar three-dimensionality starts to decrease. In other words, wavedriven circulations were therefore assumed to be essentially guided and constrained by the 3D sandbar morphology, with negligible effect of the alongshore nonuniform wave generation at the wavemaker (Castelle et al., 2010). 


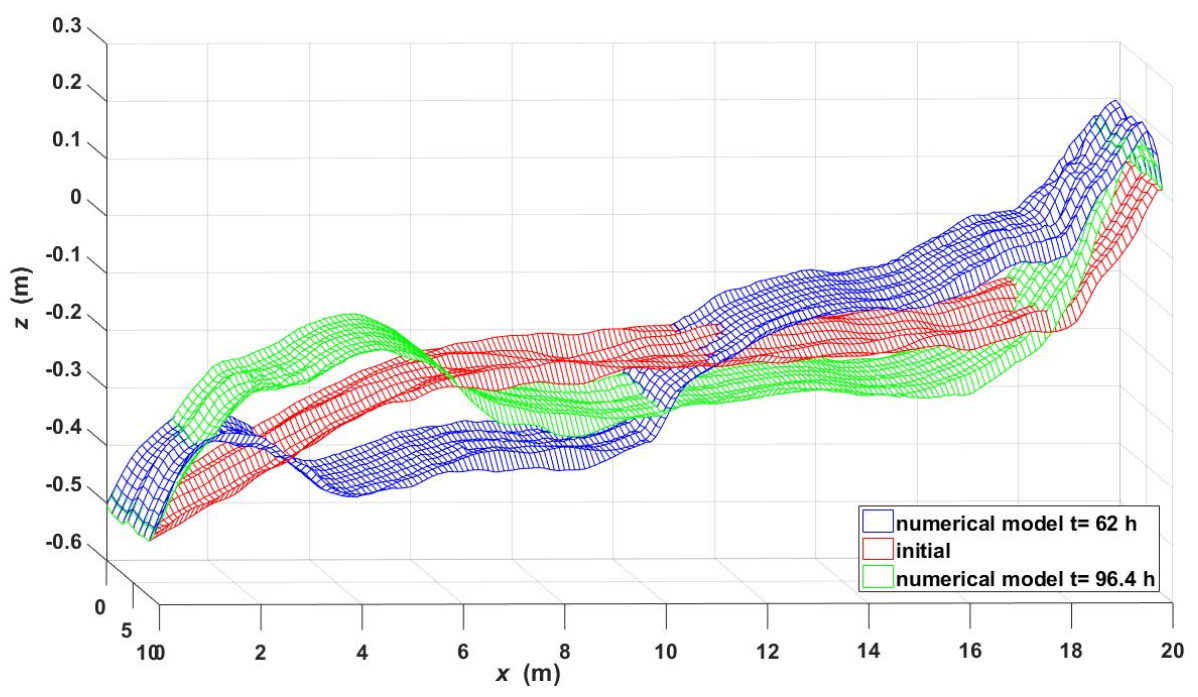

Figure 5: Three dimensional shape of the bed (bathymetry) as outcome of the numerical model. Initial (red lines), after 62 hours (blue lines) and after 96.4 hours (green lines).

The most striking feature of the results illustrated in Figure 5, is that the evolution of the bed shape over the time, follows the same sequence as that of the experiment (Figure 4). Firstly, an overall accretion of the beach face was observed over a 62 hours duration of mainly B wave conditions $\left(H_{m 0}=18 \mathrm{~cm} / T_{p}=3.5 \mathrm{~s}\right)$. During this phase, the obtained results show an onshore migration of the sediment and a significant erosion of the seaward section of the bar $(x \leq 10 \mathrm{~m})$ resulting in an overall onshore migration of the sandbar system. For this wave sequence, comparing the obtained threedimensional bathymetry with that of the experiment (Figure 6), it is shown that the accretion in the case of the numerical model is more intense and extends further seaward. Concerning the second time period $62 \leq t \leq 96.4 \mathrm{~h}$ with A wave conditions $\left(H_{m 0}=23 \mathrm{~cm}\right.$ $/ T_{p}=2.3 \mathrm{~s}$ ), an overall erosion is presented during the numerical simulation. As derived from Figure 5, the sandbar system has been migrated seaward. The comparison with the experimental data (Figure 7) shows that the erosion is less intense shoreward in the case of the numerical model and the concentration of the sediment in the zone $x \leq 6$ is higher than that of the experiment.

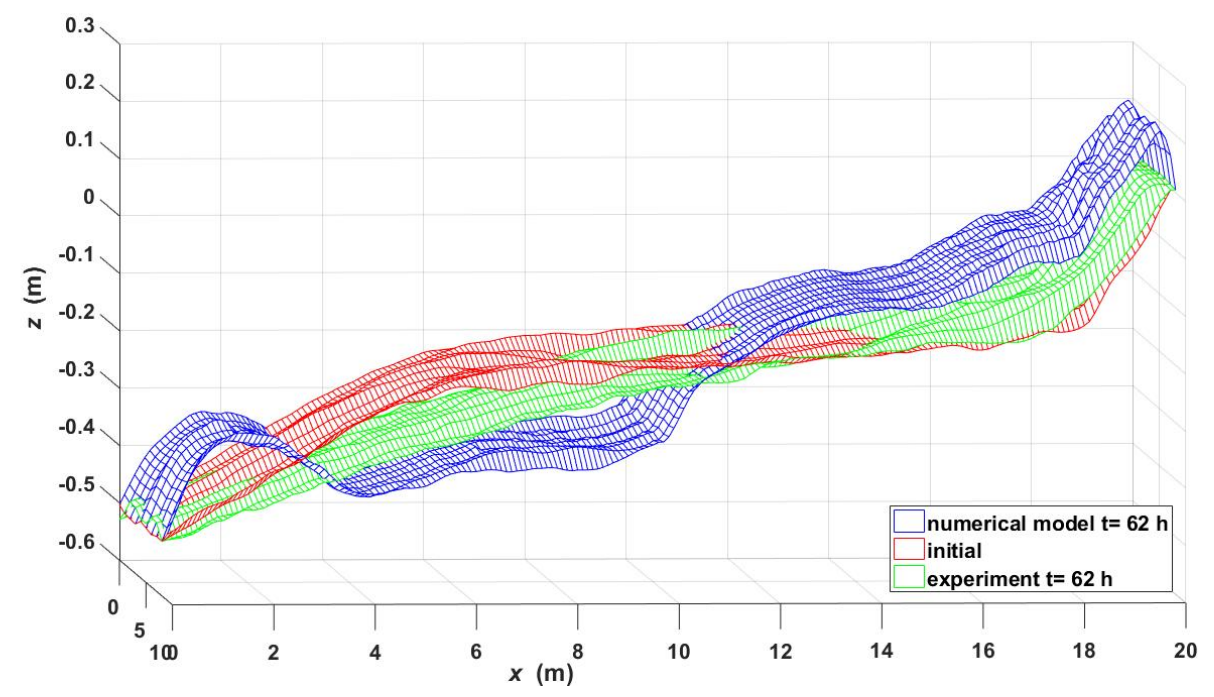

Figure 6: Three dimensional shape of the bed (bathymetry) during the first phase of simulation. Initial (red lines), numerical model (blue lines) and experiment (green lines). 


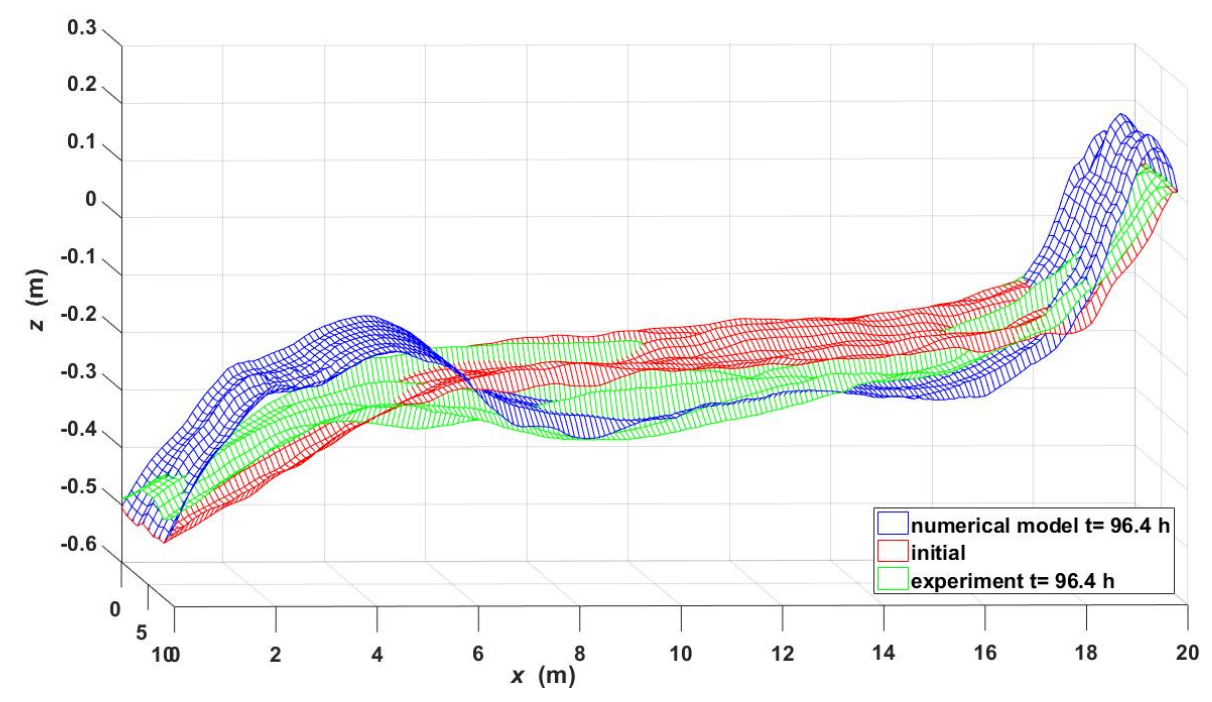

Figure 7: Three dimensional shape of the bed (bathymetry) during the second phase of simulation. Initial (red lines), numerical model (blue lines) and experiment (green lines).

The present results are direct in agreement with existing studies (Russell, 1993), (Thornton et al., 1996), which have revealed that the beach erosion is proportional to the amount of the wave energy in the coastal zone. Furthermore, it is difficult to compare the characteristics of the alongshore morphology, since the flow at the inlet of the numerical analysis is considered alongshore uniform. However, conversely to the study of (Michallet et al., 2013), these results seem to be compatible with that of Wright and Short (1984), as a decrease of the beach threedimensionality is presented during the morphological evolution. As concluted from the present work, applying the same wave climate for a long time period resulted in a decrease in the bottom evolution velocity. Hence, the beach tends towards a steady state, by reshaping the bar into an alongshore-uniform pattern. Additionally, for the comparison of the alongshore morphological characteristics, it has to be considered that the lateral boundaries in the physical model act as headlands, increasing the beach three-dimensionality. It has been assumed that the differences in the morphological evolution within and between beaches during storms are related to embayment geometry and orientation of the shore, while the sediment transport is driven by marked alongshore gradients in breaking wave height and interaction with embayment boundaries (Loureiro et al., 2012).This phenomenon does not occur during the numerical modeling, since the values at boundary cells are obtained by second order extrapolations normal to the boundary from the values inside the domain.

\section{CONCLUSIONS AND FUTURE RESEARCH}

The essential goal of this research is to further our ability to understand wave-sandbed interaction. The proposed numerical model based on shallow water equations was applied to two different categories (A, B) of shore normal irregular waves propagating over a sand bed field, and a comparison between the experimental data and the numerical results has been well performed. As derived from this study, the outcomes of the numerical model show enough accuracy for the values of the wave periods and the obtained beach profiles, but some deviations between the results of the model and the experiment have been observed concerning the characteristics of the beach three-dimensionality. Because of these deviations, the procedure of this study is based on the transition from the dissipative (D) to the reflective (R) beach state and back again, ignoring the intermediate sub-states, low tide terrace(LTT), transverse bar and rip (TBR), rhythmic bar and beach (RBB), and longshore bar trough (LBT). These correspond to the most widely accepted sequential beach state classification scheme of (Wright and Short, 1984). In order to understand the sediment motion from a design standpoint, the experiments need to be continued, including new investigations in random waves, reflective shorelines, sediment transport, and multi-reflection between reflective structures. The numerical model needs to be further developed, with potential use in design and in longterm prediction of coastal impact by waves as well. 


\section{ACKNOWLEDGEMENTS}

This work has been financed by the State Scholarships Foundation (IKY), through the program "Research Projects for Excellence IKY/SIEMENS"

\section{References}

M. J. Austin and D. Buscombe. Morphological change and sediment dynamics of the beach step on a macrotidal gravel beach. Marine Geology, 249(3-4):167 - 183, 2008. ISSN 0025-3227. doi: http://dx.doi.org/10.1016/j.margeo.2007.11.008. URL http://www. sciencedirect.com/science/ article/pii/S0025322707002940.

P. Azerad, D. Isebe, B. Ivorra, B. Mohammadi, and F. Bouchette. Optimal shape design of coastal structures minimizing coastal erosion. In Workshop on inverse problems, pages 1-5, 2005. URL http://eprints.ucm.es/30213/.

A. Bouharguane and B. Mohammadi. Minimization principles for the evolution of a soft sea bed interacting with a shallow. International Journal of Computational Fluid Dynamics, 26(3):1, Mar. 2012. URL https://hal . archives-ouvertes.fr/hal-00789827.

B. Castelle, H. Michallet, V. Marieu, F. Leckler, B. Dubardier, A. Lambert, C. Berni, P. Bonneton, E. Barthélemy, and F. Bouchette. Laboratory experiment on rip current circulations over a moveable bed: Drifter measurements. Journal of Geophysical Research: Oceans, 115(C12):2-17, 2010. ISSN 21562202. doi: 10.1029/2010JC006343. URL http://dx.doi.org/10.1029/2010JC006343. C12008.

R. Eymard, T. Gallouet, and R. Herbin. Finite volume methods. In Solution of Equation in $\mathcal{R}^{N}$ (Part 3), Techniques of Scientific Computing (Part 3), volume 7 of Handbook of Numerical Analysis, pages 713 - 1018. Elsevier, 2000. doi: http://dx.doi.org/10.1016/S1570-8659(00)07005-8. URL http://www . sciencedirect.com/science/article/pii/S1570865900070058.

Y. Goda. Random Seas and Design of Maritime Structures, volume 15 of Advanced series on ocean engineering, pages 3-4. World Scientific, Singapore, 2000.

D. Isebe, P. Azerad, F. Bouchette, B. Ivorra, and B. Mohammadi. Shape optimization of geotextile tubes for sandy beach protection. International Journal for Numerical Methods in Engineering, 74(8):1262-1277, 2008. ISSN 1097-0207. doi: 10.1002/nme.2209. URL http://dx.doi.org/10.1002/nme. 2209.

R. Krone. Aggregation of suspended particles in estuaries, pages 170-190. In: Kjerfve, B. (Ed.), Estuarine TransportProcesses. Univ. of South Carolina Press, Columbia, 1978.

C. Loureiro, O. Ferreira, and J. A. G. Cooper. Extreme erosion on high-energy embayed beaches: Influence of megarips and storm grouping. Geomorphology, 139-140:155 - 171, 2012. ISSN 0169555X. doi: http://dx.doi.org/10.1016/j.geomorph.2011.10.013. URL http://www. sciencedirect . com/science/article/pii/S0169555X11005290.

H. Michallet, B. Castelle, F. Bouchette, A. Lambert, C. Berni, E. Barthélemy, P. Bonneton, and D. Sous. Modélisation physique de la morphodynamique d'une plage barrée tridimensionnelle. In XI èmes Journées Nationales Génie Côtier - Génie Civil, page 45, Sables d'Olonne, France, June 2010. URL https://hal . archives-ouvertes.fr/hal-00861953.

H. Michallet, B. Castelle, E. Barthélemy, C. Berni, and P. Bonneton. Physical modeling of threedimensional intermediate beach morphodynamics. Journal of Geophysical Research: Earth Surface, 118(2):1045-1059, 2013. ISSN 2169-9011. doi: 10.1002/jgrf.20078. URL http://dx . doi .org/10. $1002 / j g r f .20078$.

B. Mohammadi and F. Bouchette. Extreme scenarios for the evolution of a soft bed interacting with a fluid using the Value at Risk of the bed characteristics. Computers and Fluids, 89:78-87, Jan. 2014. doi: 10.1016/j.compfluid.2013.10.021. URL https://hal . archives-ouvertes . fr/hal-01054937. 
T. Nakamura and N. Mizutani. Development of fluid-sediment-seabed interaction model and its application. Coastal Engineering Proceedings, 1(34):85, 2014. ISSN 2156-1028. URL https://journals.tdl. org/icce/index.php/icce/article/view/7920.

P. Nielsen. Coastal bottom boundary layers and sediment transport, volume 4 of Advanced Series on Ocean Engineering. World Scientific, Singapore, 1992.

C. Paola and V. R. Voller. A generalized exner equation for sediment mass balance. Journal of Geophysical Research: Earth Surface, 110(F4), 2005. ISSN 2156-2202. doi: 10.1029/2004JF000274. URL http: //dx.doi.org/10.1029/2004JF000274. F04014.

P. E. Russell. Mechanisms for beach erosion during storms. Continental Shelf Research, 13(11):1243 - 1265, 1993. ISSN 0278-4343. doi: http://dx.doi.org/10.1016/0278-4343(93)90051-X. URL http: //www.sciencedirect.com/science/article/pii/027843439390051X.

E. B. Thornton, R. T. Humiston, and W. Birkemeier. Bar/trough generation on a natural beach. Journal of Geophysical Research: Oceans, 101(C5):12097-12110, 1996. ISSN 2156-2202. doi: 10.1029/ 96JC00209. URL http://dx. doi.org/10.1029/96JC00209.

L. Wright and A. Short. Morphodynamic variability of surf zones and beaches: A synthesis. Marine Geology, 56(1):93 - 118, 1984. ISSN 0025-3227. doi: http://dx.doi.org/10.1016/0025-3227(84)90008-2. URL http://www. sciencedirect.com/science/article/pii/0025322784900082. 